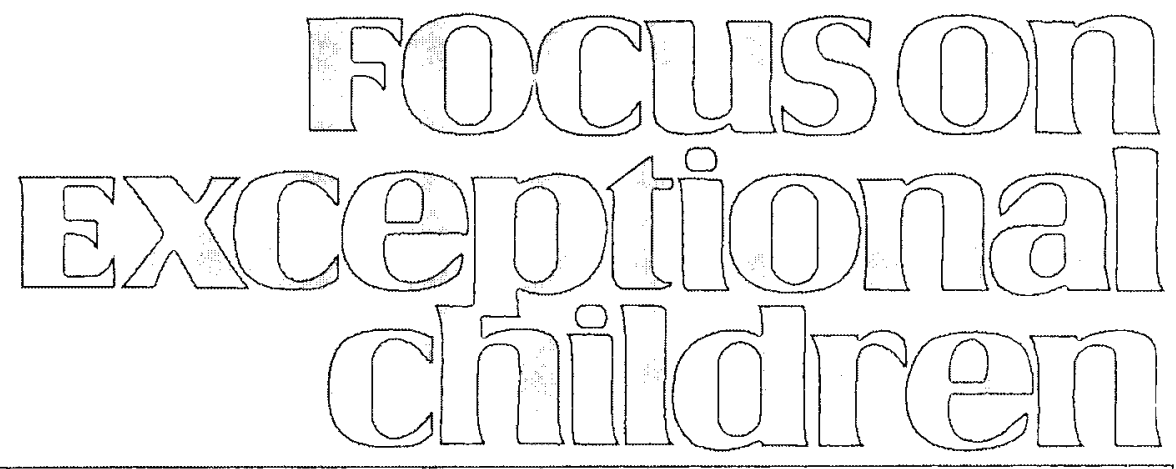

\title{
Teaching Word Identification to Students with Reading Difficulties and Disabilities
}

\author{
Carolyn A. Denton and Stephanie Al Otaiba
}

The majority of students identified with learning disabilities (LDs) are primarily impaired in reading (Fletcher, Lyon, Fuchs, \& Barnes, 2007). Many students who have other high-incidence disabilities (e.g., behavioral disorders) also have serious reading difficulties (Benner, Nelson, Ralston, \& Mooney, 2010). Although some students with disabilities are impaired in reading comprehension even though they can read words fairly accurately, the most commonly occurring reading disability is characterized by inaccurate word reading (Torgesen, 2004; 2005). In this paper, we will describe evidence-based word identification instruction for students with reading disabilities and for those with serious word reading difficulties who have not been identified as having reading disabilities, as students in these two groups have been found to respond similarly to the kind of instruction we will describe (Benner et al.; Fletcher et al.). We will refer to this group of students collectively as students with serious word reading difficulties (RD).

The need to teach students with RD to read is urgent, as the consequences of low reading proficiency are serious. Students who do not learn to read adequately are more likely to have pervasive academic difficulties and are at high risk for school dropout (Alliance for Excellent Education, 2002). Poor reading has also been related to a higher incidence of delinquency (Center on Crime, Communities, and Culture, 1997) and suicide (Daniel et al., 2006). Adding to the urgency of this situation is the fact that, with typical instruction, the vast majority of students who do not learn to read adequately in the early elementary grades remain impaired in reading as long as they are in school (Francis, Shaywitz, Stuebing, Shaywitz, \& Fletcher, 1996; Juel, 1988; Torgesen \& Burgess, 1998). In addition, early difficulties with basic reading skills typically result in limited time engaged in text reading (Juel; Stanovich, 1986); because of this lack of exposure to text, a decoding problem may eventually become a generalized reading deficit characterized by low fluency, poor vocabulary, and limited world knowledge, all contributing to impaired reading comprehension (Stanovich).

Dr. Denton is an associate professor in the Department of Pediatrics, Children's Learning Institute, at the University of Texas Health Science Center, Houston. Dr. Al Otaiba is an associate professor in the College of Education at Florida State University and the Florida Center for Reading Research. 
Unfortunately, traditional approaches to special education services often fail to close the gap between students with RD and average readers. At best, special education programs tend to stabilize the reading development of students with disabilities so that they do not fall farther behind. For example, in a study of special education reading instruction for students in Grades 3-6, Hanushek, Kain, and Rivkin (1998) found that students' standard scores in reading rose by an average of only 0.04 standard deviations per year. If a student performing at the 5 th percentile progressed at this rate, he or she would perform at only the 9 th percentile 8 years later (Torgesen, Rashotte, Alexander, Alexander, \& MacPhee, 2003).

The purpose of this article is to provide an overview of evidence-based instructional practices for teaching word reading to students with $\mathrm{RD}$. We define evidence-based practices in word reading instruction as instructional processes and routines that have been shown to be effective in teaching most students with RD to read words. Although

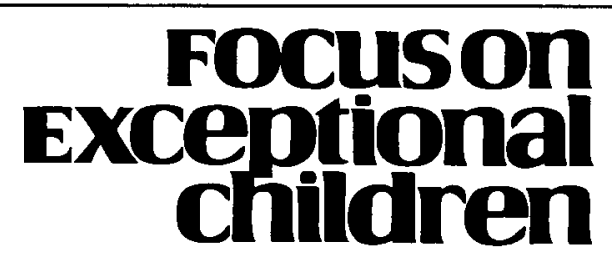

ISSN 0015-5IIX

FOCUS ON EXCEPTIONAL CHILDREN (USPS 203-360) is published monthly except June, July, and August as a service to teachers, special educators, curriculum specialists, administrators, and those concerned with the special education of exceptional children. This publication is annotated and indexed by the ERIC Clearinghouse on Handicapped and Gifted Children for publication in the monthly Current Index to Journals in Education (ClJE) and the quarterly index, Exceptional Children Education Resources (ECER). The full text of Focus on Exceptional Children is also available in the electronic versions of the Education Index. It is also available in microfilm from Serials Acquisitions, National Archive Publishing Company, P.O. Box 998, Ann Arbor, MI 48106-0998. Subscription rates: individual, $\$ 50$ per year; institutions, \$68 per year. Copyright $@ 2011$, Love Publishing Company. All rights reserved. Reproduction in whole or part without written permission is prohibited. Printed in the United States of America. Periodical postage is paid at Denver, Colorado. POSTMASTER: Send address changes to:

$$
\begin{gathered}
\text { Love Publishing Company } \\
\text { Executive and Editorial Office } \\
\text { P.O. Box } 22353 \\
\text { Denver, Colorado } 80222 \\
\text { Telephone (303) 221-7333 }
\end{gathered}
$$

\section{CONSULTING EDITORS}

Steve Graham Vanderbilt University
Ron Nelson University of Nebraska-Lincoln

Eva Horn

University of Kansas
Carrie E. Watterson Senior Editor
Stanley F. Love Publisher no instructional approach is effective for every individual student, the practices we describe are supported by converging research findings from multiple studies. To provide a foundation for this discussion of word reading instruction, we begin with a description of the reading process. Then we describe the role of assessment in teaching word reading. Next, we describe evidence-based reading instruction and intervention for students with RD, including a set of general principles for effective instruction. The next section addresses additional considerations for the implementation of effective word reading instruction.

\section{THE READING PROCESS}

Reading is a complex endeavor that is made up of multiple components, all of which must be executed and orchestrated by the reader with the goal of making meaning from printed text. The reader must quickly and accurately recognize printed words, understand the meanings of the words, and create a cohesive mental model of the meaning of the text (e.g., make sense of the text by making inferences based on connections within and beyond the current text; Snow, 2002). Gough and Tunmer (1986) proposed a simple model of the reading process that suggested that effective reading is the product of the ability to decode print and the ability to comprehend language. In other words, students must learn to recognize known words immediately, quickly and efficiently decode unknown words, and read connected text quickly and accurately. They must also develop a sufficient vocabulary, a body of world knowledge, and oral language skills that will enable them to comprehend increasingly complex language. To read advanced text, they must command a large body of general and subject-specific vocabulary and background knowledge, sophisticated syntax (i.e., language usage), and text structures (e.g., narrative, compare and contrast) commonly used in written text, including text that addresses specialized domains such as chemistry or English literature. Mature, proficient readers are able to execute many of these processes automatically, without direct attention, while simultaneously building a mental representation of the meaning of the text, monitoring their own understanding of the text, and thinking critically about the text they are reading (e.g., Ehri, 2002).

\section{Basic Reading Skills}

At the most basic level, beginning readers must become aware of individual sounds and groupings of sounds within the oral speech stream. Spoken language consists of words composed of syllables that are in turn composed of individual sounds; however, when a person listens to oral speech, these words and word parts tend to run together. The beginning reader must become aware that oral language is made 
up of these components, a competency commonly referred to as phonological awareness (Blachman, 2000). Phonemic awareness, a subcategory of phonological awareness, is the recognition that spoken words are composed of individual sounds, or phonemes. The ability to hear and manipulate the sounds within words has been found to be highly predictive of reading proficiency (Blachman; Schatschneider, Fletcher, Francis, Carlson, \& Foorman, 2004), and deficits in this area are characteristic of persons with dyslexia (Shaywitz, 2003). In addition to this awareness of sounds in spoken language, beginning readers of alphabetic languages must understand that letters and letter combinations represent spoken sounds. This is commonly called the "alphabetic principle." Although the awareness of phonemes and an understanding of the alphabetic principle normally develop in preschool through grade 1, some older students with serious word reading difficulties benefit from instruction in these basic competencies (e.g., Calhoon, 2005; Lovett et al., 2000, Torgesen et al., 2001).

\section{Word Recognition, Fluency, and Comprehension}

Accurate and quick word recognition is necessarythough not sufficient-for making meaning from print. For the most part, word recognition is accomplished in two ways-through phonological decoding (i.e., applying phonics to "break the code") and by recognizing intact words or parts of words "at sight" (Ehri, 2002). Although proficient readers use context, or the meaning of the text, to monitor their reading accuracy and to refine word identification, there is evidence that they do not rely on context as a primary way to identify unknown words (Ehri). Weak readers overrely on context in order to compensate for inadequate word-level reading ability, which is inefficient, as only about $10 \%$ of the words that are important to the meaning of passages can be inferred correctly from context alone (Gough and Walsh, 1991). As students increase in reading proficiency, they are able to recognize more and more words instantly and automatically, and reading becomes more fluent. Essentially, fluent readers have very large "sight word" vocabularies (Torgesen et al., 2003). Reading fluency is affected not only by the speed of word recognition but also by the reader's ongoing comprehension of the text, and fluent readers are able to interpret the phrasing and inflections in the text appropriately (Fuchs, Fuchs, Hosp, \& Jenkins, 2001). Fluency is highly predictive of how well students in the elementary grades will comprehend the text they read (Fuchs et al.). Researchers have had mixed findings about the relationship between fluency and comprehension in older students; in general, this relationship weakens as students progress through the upper grades (Denton et al., 2011).

Reading comprehension, the ultimate goal of the reading process, is affected by many factors, including word reading accuracy, reading fluency, vocabulary, world or background knowledge, and the ability to make inferences and strategically process text (Sweet \& Snow, 2002). This means that students with reading comprehension difficulties differ in their needs related to word reading instruction. Young children who are at risk for or experiencing reading difficulties in grades $\mathrm{K}-2$ almost always need a full program of instruction in basic decoding and word recognition, as these are the years in which children are expected to master the code and learn to recognize many high-frequency words at sight. Students in grades 3 and above who have reading difficulties may need (a) a full program of instruction in basic decoding and word recognition, (b) short-term concentrated word identification instruction focused primarily on multisyllable words and structural analysis, or (c) ongoing word study that provides only minimal support in basic word recognition but equips students for decoding and spelling complex words as well as using morphemic analysis to determine word meanings (i.e., using knowledge of meaningful word parts such as affixes and roots).

\section{THE ROLE OF ASSESSMENT IN WORD IDENTIFICATION INSTRUCTION}

Four types of assessments serve important purposes in an effective reading program. Three types of assessments are formative, meaning they are designed to provide ongoing information to educators to inform their instruction decisions: screeners, diagnostic assessments, and progress monitoring assessments. These formative assessments are used to identify students with reading difficulties, design instruction, and gauge whether students are responding adequately to instruction. The fourth type is summative assessment, designed to assess whether students have met important goals and benchmarks, typically at the end of the school year. Summative assessments include outcome measures and statewide accountability tests. All of these assessments are important, but our primary focus will be on formative assessment because of its key role in word reading instruction.

\section{Screening and Progress Monitoring Assessments}

Screening assessments are brief assessments designed to identify students who may be at risk for RD or require supplemental intervention. These brief assessments always have some degree of error; they overidentify students who do not actually need supplemental intervention (i.e., false positives) and/or fail to identify some students who do need additional intervention (false negatives) (Jenkins, Hudson, \& Johnson, 2007). There is a trade-off between false positive and false negative errors. If a screener is made more rigorous, more students will fail it, but some of these will not actually be at risk for RD; conversely, if a screener is less 
difficult, many students will pass it, but some of these actually do require additional instruction to become proficient readers. Most published screeners are designed to have a low false negative error rate since the consequences of this kind of error is that students who need intervention do not receive it. For this reason, it is important to follow screening assessments with other kinds of assessments, including progress monitoring assessments, which are brief tests that are administered repeatedly on a regular schedule in order to track students' development of key skills and competencies over time.

The purpose of screening is to determine which students are not performing on grade level or are not making appropriate growth on key skills within the scope and sequence of the reading curriculum so that their instruction can be modified or supplemental intervention can be provided. Such assessments are therefore deliberately related to the curriculum and may include a general approach known as curriculum based assessment (CBA). Shapiro (2004) described CBA as incorporating several steps: (a) assessing the academic and behavioral instructional environment, (b) determining the level of performance of a student relative to classmates, (c) identifying placement within the curriculum and identifying appropriate accommodations or differentiated instruction, and (d) monitoring ongoing progress within the differentiated instructional curriculum. The use of timed measures that are closely aligned with the curriculum, or curriculum-based measurement (CBM; Deno, 1985), to monitor students' progress toward important goals has a long and rich tradition in special education across many domains, including reading (Jenkins, Graff, \& Miglioretti, 2009).

As an example, in a school applying CBA to inform early reading instruction, kindergarten teachers may screen all students using brief curriculum based measures (CBMs) of key skills such as phonological awareness and letter knowledge. This step helps identify individual students who enter school with weaker initial skills and informs placement within the reading curriculum. Subsequently, ongoing progress monitoring using CBMs allows teachers to (a) rule out general problems within the instructional environment, (b) target students who are not performing as well as classmates, and (c) plan instructional goals and devise homogeneous small groups for supplemental intervention. Firstgrade teachers may then assess key skills that develop a little later in the sequence, such as phonemic awareness, word identification, phonemic decoding, word reading fluency, and oral reading fluency (ORF) in connected text. Evidence shows that brief measures of ORF are good indicators of growth in general reading ability in the primary grades, reflecting the development of quick and accurate word identification and closely related to reading comprehension outcomes (Fuchs et al., 2001). Despite the long history of using
CBMs like ORF to inform instruction across the primary grades (e.g., Fuchs, Deno, \& Mirkin, 1984; Stecker, Fuchs, $\&$ Fuchs, 2005), recently, some researchers have cautioned that measuring progress through repeated measurement of ORF may be unreliable when individual passages are not equally difficult, unless the scores are statistically adjusted (Francis et al., 2008).

\section{Diagnostic Assessments}

The effective use of data from diagnostic assessment is critical to the delivery of word reading instruction to students with RD. Diagnostic assessments are most often individually administered and may be either standardized or informal. The purpose of diagnostic assessment is to inform a teacher about a student's specific strengths and needs so that instruction can be designed to address these needs. Some assessments provide general information that indicates that a student needs instruction in word reading, fluency, and/or comprehension. For example, low performance on ORF CBMs would likely indicate a need for fluency instruction and possibly word identification instruction. Other individually administered tests are norm referenced, such as the widely-used Woodcock-Johnson Reading Mastery Test-Revised (Woodcock, 1987), which includes an array of reading skills, or the Test of Word Reading Efficiency (TOWRE; Torgesen, Wagner, \& Rashotte, 1999). The TOWRE assesses the speed and accuracy of reading sight words and pseudowords (as measures of phonological decoding) presented in list format in order of increasing difficulty; students have 45 seconds to read as many as they can. Norm-referenced reading tests such as these allow teachers to determine a student's reading performance relative to same-age or same-grade peers and to establish a general profile of strengths and weaknesses. For example, using the TOWRE would allow a teacher to know if a student was performing below grade level and to understand whether the student performed relatively better on sight words or on decodable pseudowords.

Other diagnostic assessments can provide teachers with precise and reliable information about students' levels of performance on important subskills in reading, data that is necessary to provide instruction designed to accelerate student progress. For example, it is necessary to know which specific phonics elements (e.g., letter-sound correspondences, silent-e word patterns) and which high-frequency words have been mastered and which need to be taught or retaught. This type of diagnostic assessment can include simple letter-sound inventories, sight word inventories, or criterionreferenced standardized assessments such as the Diagnostic Assessment of Reading (DAR; Roswell, Chall, Curtis, \& Kearns, 2005) or the Quick Phonics Screener (Hasbrouck, 2008), which can help teachers distinguish which phonetic 
patterns (e.g., CVC, CVCe) have been mastered and which have not been mastered. Valuable information to guide instruction and the pace of movement through published instructional programs may also come from placement tests and mastery tests that accompany these programs, if these assessments are administered frequently and the results are interpreted carefully. Essentially, the critical question answered by diagnostic assessment is, "What does this student already know and what does he or she need to learn?" Teachers who have precise information to answer this question can make informed decisions about what to teach during the very limited instructional time that is available to them.

\section{PROVIDING EFFECTIVE WORD-READING INSTRUCTION}

For students with RD, attaining benchmarks for proficient reading can be highly challenging. In order for students who perform below grade level to attain average levels of reading proficiency, they must make faster progress than their typically-developing peers. (Consider that, if someone is trailing in a footrace, they must run faster to overtake runners who are ahead of them.) This thought may be overwhelming to their teachers, but accelerated word reading progress $i s$ possible for students with RD. To accomplish this goal, instruction must be both effective and efficient.

To make accelerated progress, students with RD generally require more instruction and more practice than their typically-developing classmates, so it is recommended that they receive both daily classroom reading instruction and supplemental small-group reading intervention. The US Department of Education's What Works Clearinghouse suggests that students with serious reading difficulties who have not responded adequately to regular classroom reading instruction and lower intensity interventions should receive daily, intensive small-group reading intervention in addition to daily classroom reading instruction (Gersten et al., 2008).

Studies that have demonstrated the best outcomes for students with RD have been conducted in the context of smallgroup supplemental interventions. A substantial body of converging evidence supports the effectiveness of instructional reading interventions provided to students with reading difficulties in the primary grades (Benner et al. 2010; Cavanaugh, Kim, Wanzek, \& Vaughn, 2004; Ehri, Nunes, Stahl, \& Willows, 2001; Elbaum, Vaughn, Hughes, \& Moody, 2000; Torgesen, 2004; Wanzek \& Vaughn, 2007). Studies of reading interventions provided to students with identified learning disabilities have also demonstrated that it is possible to intervene successfully with these students (Swanson, 1999). For example, Torgesen et al. (2001) showed that students in grades 3-5 with severe RD can be remediated through highly intensive intervention. In studies of this type conducted with elementary-aged students, group outcomes have been generally positive, but some students have demonstrated little growth even with highly intensive intervention (e.g., Denton, Fletcher, Anthony, \& Francis, 2006). These students may need a different instructional approach, or they may need intensive instruction over a period of years rather than months.

Reviews and meta-analyses have revealed larger effects for reading interventions provided in the early stages of reading acquisition than for those provided in Grades 3 and higher. For example, Wanzek and Vaughn (2007) found larger effects for intervention provided in Grades $\mathrm{K}-1$ than $2-5$. Although the reading difficulties of students in Grades 3 to 5 can be remediated through intensive small group or one-on-one $(1: 1)$ interventions, this may be more challenging than providing intervention at early stages of reading acquisition (Torgesen, 2004; Wanzek, Wexler, Vaughn, \& Ciullo, 2010). For students with RD at the secondary level, intervention can be even more challenging (e.g., Vaughn, Cirino, et al., 2010), particularly for those with poorly developed oral language skills (Denton, Wexler, Vaughn, \& Bryan, 2008). Denton et al. speculated that such students may require highly intensive interventions over the course of several years to become adequate readers. In contrast, in the context of a brain imaging study, Simos et al. (2002) demonstrated that severely impaired readers ranging from age 7 to 17 years could be brought to average levels of word reading performance through 8 weeks of individually designed and delivered, highly concentrated reading intervention provided about 2 hours per day in a reading clinic setting, and that these changes in word reading scores were accompanied by changes in the ways the students' brains functioned when reading.

Although current research cannot assure educators that all students with RD will be able to read on grade level, a strong research base has emerged related to effective word reading instruction for these students. These findings were synthesized in the reports of the National Research Council (Snow, Burns, \& Griffin, 1998) and the National Reading Panel (NRP; 2000). These reports, along with more recent meta-analyses and research summaries (Foorman \& Torgesen, 2001; Gersten et al., 2008; Swanson, 1999; Torgesen, 2004; Wanzek \& Vaughn, 2007; Wanzek et al., 2010) have identified a set of principles for effective instruction of students with or at risk for RDs, derived primarily from common characteristics of reading instruction, that has been found to be effective in multiple scientific studies. The instructional approaches used in these studies differed in some ways, but they had important features in common.

In general, explicit instruction that is purposefully designed to target the critical content that students need to 
learn based on ongoing assessment data has been shown to be effective for students with RD. This instruction is most effective when it is delivered within structured, carefully sequenced, well-organized lessons and when it includes daily opportunities to read and respond to connected text at an appropriate level of difficulty. Students with serious RD also require intensive instruction, meaning that it is delivered to small groups of students in highly interactive formats over extended periods of time. These principles apply to both general education and classroom reading instruction for students with RD and to supplemental intensive interventions specifically designed to accelerate their reading development. In the next section we describe these evidence-based principles for providing effective instruction to students with RD.

\section{Provide Explicit Instruction}

Instruction that accelerates word reading development is highly explicit, which means that teachers use direct instruction, modeling, and timely corrective feedback so that students do not mislearn, misinterpret, or mistakenly repeat their own errors. When students with $\mathrm{RD}$ receive clear, explicit instruction, they are not left to infer information or guess what the teacher wants them to do. On the other hand, if points of confusion are not addressed and foundational skills are not mastered, students will likely continue to perform below grade level. Explicit instruction in word reading skills is a common theme in programs that have reliably produced substantial growth in students with RD. For example, Iverson and Tunmer (1993) added explicit instruction in phonics and phonemic decoding to the Reading Recovery (Clay, 1993) program, which has traditionally focused less on explicit instruction. The researchers found that even a small amount of explicit instruction in phonics increased the efficiency of the Reading Recovery program by nearly $40 \%$.

A teacher who provides explicit instruction (a) conducts frequent assessment to identify student needs and evaluate mastery of key objectives; (b) plans lessons focused on clear instructional objectives guided by assessment results; (b) clearly models or demonstrates skills and provides clear explanations of new concepts; (c) provides guided practice, checking for understanding and providing timely feedback; (d) monitors independent practice, providing feedback if needed and gradually releasing responsibility to students; and (e) monitors student progress and mastery of key objectives, providing reteaching or extended practice as necessary. Figure 1 illustrates an explicit instruction cycle that is likely to support the progress of students with RD.

\section{Plan Purposeful Instruction to Target Student Needs, Including Phonics Instruction}

Instruction that is purposefully directed at key skills related to word identification (e.g., letter-sound correspondence, irregular word recognition, recognition of commonly

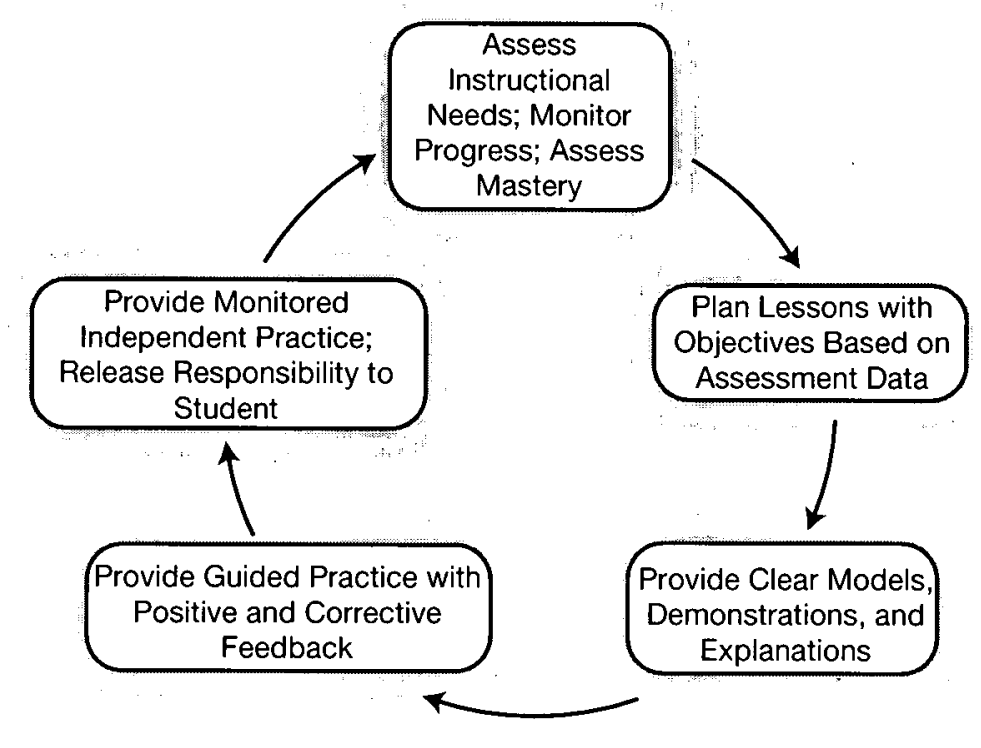

FIGURE 1.

Explicit Instruction Cycle. 
occurring patterns in words) leads to improved word reading performance (NRP, 2000; Snow et al., 1998). In explicit instruction frameworks, teachers administer diagnostic and progress monitoring assessments regularly, and they use the results of these assessments to determine and/or refine the instructional objectives for the lessons they deliver.

Students with RD benefit from instruction in phonics, and some benefit from phonemic awareness instruction, if they have severe word reading deficits and weaknesses in phonemic awareness. Phonics instruction teaches students to decode unfamiliar words. There are two basic approaches to phonics instruction, and both have been found to be effective for students in the primary grades (NRP, 2000) and for older students who need it (e.g., Abbott \& Berninger, 1999; Bhattacharya \& Ehri, 2004). In a synthetic phonics approach, students learn the sounds of individual letters then how to blend these sounds together to read words and word parts (e.g., syllables). The progression is generally from smaller to larger units. In an analogy phonics approach, students learn to recognize larger word parts and patterns by analogy to a group of known keywords. For example, students may learn the word cow as a keyword and use this knowledge to enable them to read the words now and plow. Wanzek and Vaughn (2007) completed a meta-analysis of studies of extensive small-group reading intervention (i.e., lasting over 100 hours) for students with RD in the primary grades. Results suggested that studies with the highest effects emphasized phonics instruction that incorporated either letter-sound identification with word blending or instruction in recognizing word patterns. There are examples of highly effective word reading programs for students with RD that utilize both synthetic (e.g., Mathes et al., 2005) and analogy (e.g., Gaskins, Ehri, Cress, O'Hara, \& Donnelly, 1997) approaches, as well as combinations of the two (e.g., Denton et al., 2010). Ehri, Satlow, and Gaskins (2009) found evidence that teaching students with RD to use analogies to keywords to decode unfamiliar words along with instruction in letter-sound correspondences resulted in better outcomes than analogy phonics instruction alone.

Regardless of the approach selected, word reading instruction that is likely to accelerate the reading development of students with RD must be efficient, particularly for students who are in grades 2 and above who may be a year or more behind. When teachers use precise diagnostic reading assessments like those described above to guide instruction, they are able to determine how time is best allocated during the reading lesson. For example, if a fourth grade student who is receiving basic decoding instruction has already mastered the majority of the letter-sound correspondences for the single consonants, time may be wasted on lessons that teach these skills. A better choice might be to focus on vowel sounds and letter combinations, including vowel patterns (e.g., ea, ai, igh, or) and more complex word patterns, including prefixes and suffixes (e.g., tion, dis). Students who are performing below grade level do not have time to waste, and effective teachers keep this in mind as they plan for and implement lessons. Scripted and other highly structured published reading programs can be adapted to individualize instruction if they include welldesigned placement and mastery tests. Results from these tests can inform decisions to move quickly through or even skip over lessons or activities that focus on skills the students have already mastered or to reteach or supplement lessons that focus on skills the students need to master (Denton, Anthony, Parker, \& Hasbrouck, 2004; Denton et al., in press).

\section{Provide Clear Demonstrations and Explanations}

Students who are easily confused are more likely to be successful when teachers provide clear demonstrations and explanations. When teaching a skill or strategy, such as decoding a multisyllable word or reading a silent $e$ word, effective teachers first demonstrate or model by showing the students what they want them to do. When teaching strategies, teachers can "think aloud," talking through each step of a process that will ultimately be performed "in the head." When teaching concepts or items of knowledge, teachers can provide clear statements and explanations, providing both examples and nonexamples of a concept.

\section{Provide Extended Opportunities for Guided and Independent Practice}

After teachers model new skills or explain new concepts, students practice, first with teacher support and feedback, and then independently. Students with RD typically need to spend more time practicing skills they have learned than typically developing readers do. Because students with $\mathrm{RD}$ must practice the very skills that are most challenging for them to learn, evidence shows it is vital that teachers provide frequent opportunities for both guided and independent practice, including cumulative review. This is important in light of research showing that students with reading disabilities require more opportunities to correctly pronounce new words before they are able to recognize them automatically (Reitsma, 1990). Repeated practice reading individual words, as well as repeated practice reading connected text, leads to improved reading fluency (Levy, Abello, \& Lysynchuk, 1997; Meyer \& Felton, 1999), particularly when it is accompanied by teacher feedback (Chard, Vaughn, \& Tyler, 2002).

During guided practice, students practice newly taught skills in isolation, as well as the application of these skills in reading and writing, with teacher feedback. Students with RD particularly benefit from supportive feedback that is immediate, be it corrective or positive. Corrective feedback 
prevents students from practicing and habitualizing their errors. Powerful praise statements incorporate comments that attribute a student's improved reading performance to his or her own hard work and sustained effortful attention. Rather than offering a generic "Good job," a teacher might say, "You must feel proud that your practice on this set of words is paying off. You did not miss any today when I timed you. You achieved your goal of 40 words per minute .... Way to go!" Note how this targeted praise can be paired with tracking growth towards a goal or benchmark on progress monitoring assessments.

Students also need independent practice, during which they implement skills and strategies without teacher support (but with close teacher monitoring and reteaching when necessary). During the guided-to-independent practice sequence, responsibility for performance is gradually released from the teacher to the student.

Guided and independent practice should include not only newly taught items but also previously taught items in the form of cumulative practice over time. Proficient reading requires that key skills are practiced to the point that they are both firm and fluent. In other words, students should consistently demonstrate mastery of basic word reading skills and be able to apply them automatically, with little conscious attention. This principle can be illustrated with a high-frequency irregular word. When the word is first learned, students may be inconsistent in identifying it, remembering the word at times and forgetting it or confusing it with other words at other times. It may also take several seconds for students to recall the word during this phase of learning. In order to read fluently and accurately, students must be able to identify this frequently occurring word just as automatically as a proficient adult reader does. Cumulative practice also provides students with RD with the opportunity to discriminate between previously and newly learned items such as letter-sound correspondences and high-frequency irregular words. For example, imagine that a student has previously learned to recognize the words was and what. In a new lesson, the student learns the word when. The student may become confused when the new word is introduced, and accuracy on the previously learned words may decline. The student will benefit from opportunities for practice integrating new and prior learning.

\section{Monitor Mastery of Key Objectives and Reteach if Needed}

It is important that students with RD master reading skills and strategies before they are introduced to new skills and strategies (Gersten et al., 2008). Effective reading instruction for students with RD is designed so that easier skills form a foundation for more difficult skills. If students attempt to learn the more advanced skills before they have mastered essential pre-skills, they may experience great difficulty or failure. Many high-quality published reading programs designed for students with reading difficulties include mastery tests designed to assess student proficiency on taught skills. Teachers can also monitor mastery through frequent administration of criterion-based informal assessments such as letter-sound or sight word inventories.

While teaching to mastery is important, this consideration must be balanced with the need to move students through the curriculum at a pace that will enable them to "close the gap" with typically-developing readers. On one hand, students with RD should experience a high level of successful or accurate responses in every lesson. Students with RD tend to progress more quickly when instruction is designed so that they can achieve success with teacher support, much like Vygotsky's “zone of proximal development" (1978). However, it is also important that instruction does not progress at so slow a rate that students progress through only a small part of the curriculum during a school year, as this will likely be ineffective in accelerating their reading development (Denton, 2010).

Judgements about insisting on a high level of mastery may be particularly challenging when instruction is delivered in small groups rather than individually. In our professional development sessions, teachers frequently ask whether an entire group should be kept on a lesson for an extended period of time because one student in the group has not passed a mastery test. We advise one of these approaches:

- If a student occasionally struggles to master objectives, provide 5 to 10 minutes of extra $1: 1$ instruction to that student so that he or she can achieve mastery and the group can progress at an appropriate rate.

- If one student consistently requires considerably more time to master key skills than others in his or her group, and if there is another small group that moves at a pace that is more appropriate for that student, rearrange the intervention schedule so that the student can be moved to a different group.

- If it is not possible to move the student to a different group, go on to the next lesson or unit, but modify instruction to incorporate additional instruction and practice on the items the student failed to master. This kind of modification can be made even within a scripted reading program.

- If none of these approaches is successful, the student may require $1: 1$ instruction for a time rather than small-group instruction.

\section{Provide Carefully Sequenced, Well-Organized Lessons}

Effective word reading instruction for students with RD is carefully sequenced, so that easier skills are presented and mastered before more complex skills are introduced, and 
potentially confusing elements are separated. Skills and concepts are taught in a predetermined order according to a logical scope and sequence so students are not asked to perform challenging tasks when they lack the necessary subskills. A well-sequenced beginning reading program that implements a synthetic phonics approach would introduce new letter-sound correspondences in a sequence designed so that letters are separated from each other if they are visually similar (e.g., $b$ and $d ; p$ and $q ; v$ and $w$ ) or have similar sounds (e.g., "short" $e$ and $i$ ). In most effective reading intervention programs, the amount of new information introduced at any one lesson is limited to ensure that students master the key objectives. Much of each lesson consists of practice of previously introduced skills, strategies, and concepts and the integration of these with the newly taught material.

Published reading programs that are developed in this way are typically called systematic programs. It is important to note, however, that systematic does not mean scripted. Some reading programs are highly prescriptive, or scripted, and are also systematic. However, unscripted programs can also be well-organized based on a carefully constructed scope and sequence.

A carefully developed scope and sequence for teaching basic word reading using a synthetic phonics approach typically follows a developmental trajectory that begins with teaching high utility consonant letter-sound correspondences. For students who struggle to master these lettersound correspondences, initial instruction may focus on helping students learn to recognize and be aware of the spelling of their own names (Ehri, 2002). Then, as students begin to master letter-sound correspondences, teachers may deliberately introduce high-frequency initial and ending sounds (e.g., m, s, t, n) and short vowels (e.g., a). Teachers teach students how to blend sounds together in order to phonemically decode words (/D//a//d/ is "Dad") and teach how to segment in order to encode or spell "Dad." Students are also taught a small number of very useful high-frequency irregular words. Thus, children are able to begin to read simple words and sentences very early in the instructional sequence. Next, teachers introduce consonant digraphs and long vowels, followed by vowel digraphs and variant vowel digraphs and diphthongs. It is important to note that even when letter-sounds are taught in isolation, it is essential to quickly offer opportunities for students to practice reading words using those letter sounds. For more advanced students, teachers provide instruction in recognizing word patterns such as syllable types and in using morphemic analysis to read and determine the meaning of multisyllabic words.

Instruction in high-frequency words and irregular words is also important. Oftentimes, teachers use the terms sight words, high frequency words, and irregular words interchangeably.
Strictly speaking, irregular words are those that cannot be decoded using the most common sounds of the alphabet letters (e.g., was, of) or that do not follow typical phonics rules (e.g., love, give). These must be recognized as units, "at sight." However, it is important to remember that, to children who know only a small group of letters, many other words are nondecodable. The important determinant of which words are taught as early "sight words" is how frequently they occur in children's text and their usefulness in producing meaningful text that the students will be able to read using the skills they have been taught. To be fluent readers, students need to ultimately be able to recognize a large group of frequently occurring English words "at sight" without having to decode them, even if they are decodable.

\section{Provide Daily Opportunities to Read and Respond to Connected Text}

Students with RD spend much less time reading connected text than typically developing readers (Juel, 1988). Lack of reading practice is related to low reading fluency as well as limited word and world knowledge, all contributing to impaired comprehension. Just as when learning any skill, such as dribbling a basketball or playing the trumpet, practicing text reading leads to proficiency and automaticity.

Students who are learning to decode need to practice reading connected text in order to apply the isolated skills they are learning. Teachers cannot assume that these skills will generalize automatically (Levy et al., 1997): Students who are able to recognize words in word-reading drills may not apply the same skills when they are reading connected text. Particularly older students, who tend to habitualize ineffective ways of interacting with text (e.g., guessing words using the initial letters, skipping difficult words, waiting to be told unknown words), may struggle to replace old habits with newly learned strategies and processes. For this reason, at least a portion of daily text reading should be guided by the teacher, who can prompt the students to apply what they have learned and provide instructional scaffolding to support them as they learn to apply new skills and strategies and "orchestrate" the complex processing that contributes to proficient reading. Teachers can incorporate a discussion of the content or meaning of the text during this reading experience so that students understand that comprehension is the goal of reading. Having students construct oral or written responses to text can also help to focus their attention on the message of the text. Moreover, students with RD need instruction in text-level processes such as vocabulary and comprehension in addition to word identification instruction. For example, teaching middle school students a strategy for summarizing text at their instructional reading levels can prepare them to comprehend more complex text as decoding proficiency increases. 


\section{Text Selection}

Two considerations are important to text selection for students with RD: text difficulty and decodability. In order to increase the likelihood that students with $\mathrm{RD}$ will be successful when they read text, it is important to provide them with text on their instructional or independent reading levels. Throughout most of their school experience, students with RD are asked to read textbooks and other materials that are too difficult for them, which often results in frustration, feelings of helplessness, and problem behaviors.

Students with RD may be provided with three types of text: (a) decodable text that is aligned with a reading program's scope and sequence, (b) "phonics readers" that can provide students with practice reading text that contains many examples of elements they are currently learning (e.g., a story containing many silent- $e$ words), and (c) nondecodable text at students' instructional reading levels for practice generalizing reading strategies beyond decodable text. Decodable text can be read using the phonics elements (e.g., letter-sound correspondences) and intact words (i.e., sight words) that have been previously taught; strictly speaking, text can only be termed "decodable" in relation to a particular instructional sequence (e.g., the scope and sequence of a specific reading program). These texts are constructed so that they will provide ample repetition of high-utility, highfrequency words and newly learned phonics patterns contextualized within thematic structures.

Particularly in the early stages of reading acquisition, there are advantages to using texts with a high density of known high-frequency words and decodable words: These texts (a) allow students to apply skills and strategies (e.g., "sounding out" words) in contexts in which these strategies will "work" for most of the words in the text, increasing the probability of successful reading experiences, and (b) ensure that students receive many opportunities, within a single reading of the text, to pronounce important words multiple times (Hiebert \& Fisher, 2002). A disadvantage of text that is specifically written to be decodable is that it may lack rich vocabulary and content to support the development of reading comprehension. This problem should become less salient as students master a larger pool of phonics elements and recognizable words.

Despite some advantages of using decodable text in early decoding development, some effective early reading intervention programs do not use decodable text. For example, in one of the first-grade interventions tested by Mathes et al. (2005) and later by Denton et al. (2010), students read text that was not designed to be decodable but was leveled according to difficulty using the text leveling system developed for the guided reading approach (Fountas \& Pinnell, 1996). Outcomes for this intervention were strong, both when implemented by members of the research team
(Mathes et al.) and by regular school district employees (Denton et al.). In a study that experimentally compared the effects of decodable vs. nondecodable text in early reading intervention, Jenkins, Peyton, Sanders, and Vadasy (2004) found no significant differences in student outcomes when the same intervention was provided to at-risk first graders with decodable and nondecodable text. Decodable text may be best thought of as a form of scaffolding that can be gradually phased out as students develop the ability to read more complex words, and teachers may purposefully incorporate nondecodable text and phonics readers when they are appropriate to promote generalization of skills to more authentic reading experiences.

\section{Provide Instruction to Small Groups of Students with Similar Needs}

Students with reading difficulties benefit from instruction delivered to small groups of students with similar instructional needs. The primary advantage of this instructional arrangement is that it potentially increases the percentage of time in each lesson in which students are actively involved in activities that address their instructional needs.

\section{Classroom Reading Instruction}

A growing but converging evidence base indicates that classroom reading teachers who group their students homogeneously for instruction and who individualize or differentiate what they do in small group instruction have students with significantly greater reading outcomes (Al Otaiba, Connor, et al., in press; Connor, Morrison, Fishman, Schatschneider, \& Underwood, 2007). In a meta-analysis of the effects of within-class grouping in regular education classes, Lou et al. (1996) found that across different subject areas, group sizes of 3-4 yielded effect sizes that were twice as large as those for groups of $8-10(E S=.22$ vs. $E S=.11$, respectively). Moreover, low-ability students benefited more than medium- or high-ability students ( $\mathrm{ES}=.37$ vs. $\mathrm{ES}$ $=.19$ and $\mathrm{ES}=.26$, respectively). In a study that specifically examined outcomes in reading, Taylor, Pearson, Clark, and Walpole (1999) found that first- through third-grade teachers in more effective schools spent more than twice as much time as those in less effective schools in small-group instruction for reading.

\section{Supplemental Reading Intervention}

Gersten et al. (2008) recommended that supplemental intervention for students with severe RD that is resistant to remediation be provided 1:1 or in very small groups. An advantage of such small-group instruction is that each student has many opportunities to respond and the teacher is able to monitor and provide appropriate feedback to every student. A meta-analysis by Elbaum et al. (2000) found 
strong effects for 1:1 instruction provided to students with reading difficulties, and, in their synthesis of studies of extensive reading interventions for students in the primary grades, Wanzek and Vaughn (2007) found that higher effects were demonstrated when interventions were provided 1:1 or in very small groups (e.g., groups of 2 or 3 ) relative to interventions provided in larger groups.

Specifically, in studies that experimentally manipulated group size, Iversen, Tunmer, and Chapman (2005) and Vaughn and Linan-Thompson (2003) both found that reading interventions delivered in groups of two or three were as effective as the same interventions delivered in 1:1 formats. Some students with serious RD may require 1:1 instruction, although some studies have indicated that interventions for students with RD provided in very small groups were successful. For example, Denton et al. (2006) provided highly intensive intervention to severely impaired readers in groups of two, finding that, on average, students made considerable growth in decoding, fluency, and comprehension; however, some students did not respond adequately to this intervention. It is probably advisable to make individual decisions about intervention group size based on the nature and extent of a student's impairment in reading, as well as any accompanying attention or behavior challenges. Naturally, resources will also be a consideration.

\section{PROVIDING EFFECTIVE INSTRUCTION: OTHER CONSIDERATIONS}

In addition to the principles for effective instruction discussed previously, it is important that educators carefully select instructional programs implemented in reading instruction and that the teachers who will deliver the instruction have the necessary professional development to do so successfully. Finally, educators should be prepared to increase the intensity of supplemental interventions to address the needs of students who do not respond readily to less intensive instruction.

\section{Selecting Published Programs}

Since government initiatives such as No Child Left Behind began to stress the use of reading programs with scientific evidence of effectiveness, publishers have promoted nearly all programs as "research based." It can be challenging to evaluate these claims or the quality of the research that is purported to support these programs. It may be helpful for practitioners to consider two categories of programs-those that are "evidence based" and those that are "research validated." Evidence-based programs typically incorporate the principles of effective instruction for students with reading difficulties that were described earlier in this article. Thus, they are based on research evidence, but the effects of these specific programs may not have been evaluated in scientific studies. Table 1 contains a list of characteristics that can be used to determine the extent to which a program is evidence based.

In contrast, research validated programs have been shown to be effective in studies that specifically evaluated those programs. The "gold standard" for a research-validated program is that it has been studied in more than one randomized, controlled experiment in which some students received the program and others did not, and it has produced consistently positive results with different groups of students. Several programs with this level of evidence are currently available for providing supplemental intensive reading intervention to younger students. Appreciably less research has been conducted to evaluate core reading programs used in classroom instruction and intervention programs designed for secondary students with RD, although

\section{TABLE 1. \\ Characteristics of an Evidence-Based Word Study Program for Students with Seri- ous Word-Reading Difficulties.}

- Addresses decoding (phonics), word recognition (highfrequency and irregular "sight" words), and reading fluency. May also address phonemic awareness and spelling. For older students, includes instruction in recognizable word patterns such as affixes and syllables.

- Is appropriate for students who will be instructed in terms of age, reading level, and instructional needs.

- Presents phonics elements and high-frequency words in a logical order, progressing from easier to harder skills and separating elements that are visually confusing $(b / d$, $\mathrm{p} / \mathrm{q}, \mathrm{m} / \mathrm{n}$ ), have similar sounds $(\mathrm{e} / \mathrm{i})$, or may be confusing because they are voiced and voiceless pairs that are produced with similar mouth positions (e.g., b/p or $f / v$ ).

- Designed for the delivery of explicit instruction (directly teaching and modeling content and skills, providing guided and independent practice).

- Includes extended opportunities to practice newly learned skills, including cumulative practice.

- Provides assessments to be administered at regular intervals to assess student mastery of instructed skills, including placement tests or procedures.

- Includes, or is designed to correlate with, text of increasing difficulty, in which students can apply the skills they are learning. 
some evidence-based intervention programs are available. If a research-validated program is unavailable, practitioners can determine whether a program is evidence based and likely to have good results by applying standards like those discussed in this article (i.e., Does the program provide explicit instruction? Is it organized according to a clear scope and sequence?) However, the greatest likelihood of success is associated with the use of programs that have undergone rigorous research.

\section{Core Reading Programs for Classroom Instruction}

Researchers have demonstrated that reading outcomes are stronger when classroom teachers use an explicit core reading instructional program that is well organized and that emphasizes teaching code-focused skills than when teachers use less explicit and less systematic programs. Foorman, Francis, Fletcher, Schatschneider, and Mehta (1998) directly tested the effectiveness of core reading programs in a large study involving roughly 70 first- and second-grade classrooms. Specifically, children whose teachers used core reading programs that emphasized direct instruction and that included controlled vocabulary text showed significantly more word reading improvement than children taught with a core program that was less direct and less explicit. A second large-scale study conducted by Foorman and colleagues also examined the effect of explicit and systematic core reading programs in conjunction with professional development (Foorman et al., 2003). This multiyear study involved three cohorts and over 4,800 students who attended struggling schools. Foorman and colleagues reported that children whose teachers used systematic and explicit reading curricula that explicitly linked phonemic awareness and the alphabetic principle in kindergarten achieved reading performance that was at the national average. Most commercially available core reading programs published after the NRP (2000) report that claim to be evidence based contain instructional materials and provide routines that support explicit and systematic instruction in phonemic awareness and word recognition, at least in the early grades (Al Otaiba, Kosanovich-Grek, Torgesen, Hassler, \& Wahl, 2005).

\section{Programs for Supplemental Intervention}

Research-validated programs are available for providing supplemental intervention to students with RD, particularly in the primary grades. A smaller number of programs have been adequately tested with older students. One characteristic that differentiates these programs is that they may be more or less prescriptive.

In highly prescriptive programs (e.g., Osborn, 1995), lessons are preplanned, and the verbiage used by the teacher during the lesson is scripted. An advantage of scripted lessons is that students receive carefully constructed instruction delivered using consistent language. From the teacher's point of view, lesson preparation consists primarily of reading and practicing delivery of the lessons so that they do not appear to be reading the scripts while they teach and so that they are freed up to observe the students and provide them with effective feedback. A disadvantage of scripted programs is that it may be difficult for teachers to individualize instruction when students already know content that is included in future lessons or when they fail to master content that has already been taught. These programs are normally designed so that students progress through each lesson in sequence, but completing the entire sequence can take from 1 to even 2 years.

Less prescriptive programs can also be used to provide well-organized, structured intervention. The key is that they must have a recommended or incorporated scope and sequence to guide the order in which skills are introduced. Some unscripted programs (e.g., Sprick, Howard, \& Fidanque, 1998) provide sequential, structured lesson materials such as daily lesson sheets and teacher guides that carefully describe each lesson. One less prescriptive research-validated program (Denton \& Hocker, 2006) provides a framework for the daily lesson, carefully described teaching activities, and a sequence for introducing phonics skills and high-frequency words, but it allows for considerable flexibility so that teachers can plan lessons based on ongoing diagnostic assessments that are included with the program.

\section{Reviews of Reading Programs}

Several groups have published reviews of currently available reading programs. The What Works Clearinghouse (WWC), sponsored by the US Department of Education, provides ongoing reviews of programs by applying rigorous standards to evaluate the quality of research conducted specifically to evaluate the programs. A tutorial about how the WWC works is available at http://ies.ed.gov/ncee/wwc/ help/tutorials/tour.asp. The Florida Center for Reading Research (www.fcrr.org) has posted reviews of many programs. Finally, expert committees have reviewed the quality of research supporting specific reading assessment tools and intervention programs for the National Center for Response to Intervention (http://www.rti4success.org).

\section{Teacher Preparation}

Selecting an evidence-based or research-validated instruction program does not ensure success; it matters what teachers $d o$ with the programs they implement. The first step toward ensuring that evidence-based instruction and intervention are well implemented is to ensure that teachers have the requisite knowledge to use data to inform instruction (Al Otaiba \& Lake, 2007; Al Otaiba, Lake, Gruelich, Folsom, \& Guidry, in press). Al Otaiba et al. demonstrated that students 
whose kindergarten teachers were provided data, coaching, and web-based guidance to individualize instruction outperformed the reading performance of students whose teachers did not receive this support by a half a standard deviation. Another recent study conducted by Piasta, Connor, Fishman and Morrison (2009) showed that delivering more instruction, when classroom teachers had very little knowledge about how to teach code-focused skills, was associated with lower student scores than delivering less instruction. This finding emphasizes that no program is "teacher-proof" and that teacher knowledge matters.

Supplemental reading interventions for students with serious RD should be provided by well-qualified teachers with the training necessary to implement intervention programs with high fidelity and to respond appropriately to the needs of the students. Students with RD may be difficult to teach; they have been found to have problems in phonological processing, processing speed, and verbal working memory, and they often have challenging behaviors and/or attention deficits (Al Otaiba \& Fuchs, 2002; Fletcher et al., in press; Nelson, Benner, \& Gonzalez, 2003). Providing effective, individualized intervention to these students places large demands on teachers' knowledge and skills and requires the capacity to make quick instructional decisions in order to respond appropriately to struggling learners.

\section{Increasing the Intensity of Supplemental Intervention}

Students who do not respond well to regular classroom instruction and typical interventions (e.g., small-group tutoring) need interventions of increased intensity. The intensity of reading interventions can be increased by reducing group size and by increasing the amount of time in intervention by either extending the length of daily lessons, providing lessons more frequently, or providing intervention over an extended period of time. Intervention intensity can also be increased by raising the percentage of each intervention session during which students are actively involved in focused instruction that is aligned with their instructional needs. Pacing of instruction within lessons is quick but responsive to student needs for "think time," feedback, and reteaching, and every lesson incorporates many teacher-student interactions (Vaughn, Denton, \& Fletcher, 2010; Warren, Fey, and Yoder, 2007).

An important determiner of the intensity of an intervention is the dosage of the intervention students receive. Dosage, or the hours of intervention provided, is determined by the length of individual teaching sessions, how many times per week they are provided, and the overall duration. of the intervention. Gersten et al. (2008) recommended that interventions for students with RD who have been previously unresponsive to lower intensity interventions should consist of individualized, "concentrated instruction" delivered in "multiple and extended instructional sessions daily" ( $p$. 10). The number of months spent in intervention will depend on the needs of the students and other aspects of instructional intensity such as group size, the length of daily lessons, and how time is used during each lesson. Researchers have provided interventions to students with severe reading difficulties at the elementary level for 50 to 60 minutes per day over an entire school year, with generally positive group outcomes (e.g., Blachman et al., 2004; Vaughn et al., 2009); however, some students with reading disabilities will need more extensive intervention, perhaps over several years.

\section{CONCLUSION}

Many students in both the elementary and secondary grades struggle with word reading. Fortunately, a strong research base evaluates effective word reading instruction for these students. For students with severe word reading problems, intervention may be challenging and require considerable resources, including daily small-group targeted intervention provided over the course of years. Given the consequences of continuing reading failure to both students and society, we suggest that the effort and resources are justified. Implementing the approaches and tools identified by research may make a life-long difference for many individuals. McCray, Vaughn, and Neal (2001) interviewed middle school students with serious reading problems; in a response that reflected a major theme of the research, a girl expressed a strong desire to learn to read, "I would love to learn my letter sounds again and learn how to pronounce words right. It would be good if I could figure out what words mean and could figure out what those stories mean" (p. 26).

\section{AUTHOR NOTE}

This work was supported by grants P50 HD052117 and P50HD052120 from the Eunice Kennedy Shriver National Institute of Child Health and Human Development (NICHD). The content is solely the responsibility of the authors and does not necessarily represent the official views of the NICHD or the National Institutes of Health.

\section{REFERENCES}

Abbott, S. P., \& Berninger, V. W. (1999). It's never too late to remediate: Teaching word recognition to students with reading disabilities in grades 4-7. Annals of Dyslexia, 49, 223-250.

Al Otaiba, S., Connor, C. M., Folsom, J., Greulich, L., Meadows, J., \& $\mathrm{Li}, \mathrm{Z}$. (in press). Assessment data-informed guidance to individualize kindergarten reading instruction: Findings from a cluster-randomized control field trial. Elementary School Journal.

Al Otaiba, S., \& Fuchs, D. (2002). Characteristics of children who are unresponsive to early literacy intervention: A review of the literature. Remedial and Special Education, 23(5), 300-316. 
Al Otaiba, S., Kosanovich-Grek, M. L., Torgesen, J. K., Hassler, L., \& Wahl, M. (2005). Reviewing core kindergarten and first grade reading programs in light of No Child Left Behind: An exploratory study. Reading and Writing Quarterly, 21, 377-400.

Al Otaiba, S., \& Lake, V. (2007). Preparing special educators to teach reading: Using classroom-based assessments to judge response to intervention. Reading and Writing, 20, 591-617.

Al Otaiba, S., Lake, V. E., Greulich, L., Folsom, J. S. \& Guidry, L. (in press). Preparing beginning reading teachers: An experimental comparison of initial early literacy field experiences. Reading and Writing: An Interdisciplinary Journal.

Alliance for Excellent Education (2002). Every child a graduate: A framework for an excellent education for all middle and high school students. Washington, DC: Author. Retrieved from http://www.all 4ed.org/files/archive/publications/EveryChildAGraduate/every.pdf

Benner, G. J., Nelson, J. R., Ralston, N. C., \& Mooney, P. (2010). A meta-analysis of the effects of reading instruction on the reading skills of students with or at risk of behavioral disorders. Behavioral Disorders, 25(2), 86-102.

Bhattacharya, A., \& Ehri, L. C. (2004). Graphosyllabic analysis helps adolescent struggling readers read and spell words. Journal of Learning Disabilities, 37, 331-348.

Blachman, B. (2000). Phonological awareness. In M. Kamil, P. Mosenthal, P. Pearson, \& R. Barr (Eds.). Handbook of reading research (Vol. 3, pp. 483-502). Mahwah, NJ: Erlbaum.

Blachman, B. A., Schatschneider, C., Fletcher, J. M., Francis, D. J., Clonan, S., Shaywitz, B., \& Shaywitz, S. (2004). Effects of intensive reading remediation for second and third graders. Journal of Educational Psychology, 96, 444-461.

Calhoon, M. B. (2005). Effects of a peer-mediated phonological skill and reading comprehension program on reading skill acquisition of middle school students with reading disabilities. Journal of Learning Disabilities, 38(5), 424-433.

Cavanaugh, C. L., Kim, A.-H., Wanzek, J., \& Vaughn, S. (2004). Kindergarten reading interventions for at-risk students: Twenty years of research. Learning Disabilities: A Contemporary Journal. $2(1), 9-21$.

Center on Crime, Communities, and Culture (1997). Education as crime prevention (Occasional Paper Series No. 2) Retrieved from http://www.prisonpolicy.org/scans/research_brief_2.pdf

Chard, D. J., Vaughn, S., \& Tyler, B. J. (2002). A synthesis of research on effective interventions for building reading fluency with elementary students with learning disabilities. Journal of Learning Disabilities, 35(5), 386-406.

Clay, M. M. (1993). Reading recovery: A guidebook for teachers in training. Portsmouth, NH: Heinemann.

Connor, C. M., Morrison, F. J., Fishman, B. J., Schatschneider, C., \& Underwood, P. (2007). The early years: Algorithm-guided individualized reading instruction. Science, 315, 464-465.

Daniel, S. S., Walsh, A. K., Goldston, D. B., Arnold, E. M., Reboussin, B. A., \& Wood, F. B. (2006). Suicidality, school dropout, and reading problems among adolescents. Journal of Learning Disabilities, $39,507-514$

Deno, S. L. (1985). Curriculum-based measurement: The emerging alternative. Exceptional Children, 52, 219-232.

Denton, C. A. (2010, February). The impact of instructional variables on outcomes in tier 2 first grade reading intervention. Paper presented at the annual Pacific Coach Research Conference, Coronado, CA.

Denton, C. A., Anthony, J. L., Parker, R., \& Hasbrouck, J. E. (2004). The effects of two tutoring programs on the English reading development of Spanish-English bilingual students. Elementary School Journal, 104, 289-305.

Denton, C. A., Barth, A., E., Fletcher, J. M., Wexler, J., Vaughn, S., Cirino, P. T., Romain, M., \& Francis, D. J. (2011). The relations among oral and silent reading fluency and comprehension in middle school: Implications for identification and instruction of students with reading difficulties. Scientific Studies of Reading, 15 , 109-135. DOI: 10.1080/10888431003623546.

Denton, C. A., Cirino, P. T., Barth, A. E., Romain, M., Vaughn, S., Wexler, J., Francis, D. J., \& Fletcher, J. M. (in press). An experimental study of scheduling and duration of "tier 2" first grade reading intervention. Journal of Research on Educational Effectiveness.

Denton, C. A., Fletcher, J. M., Anthony, J. L., \& Francis, D. J. (2006). An evaluation of intensive intervention for students with persistent reading difficulties. Journal of Learning Disabilities, 39, 447-466.

Denton, C. A., \& Hocker, J. L. (2006). Responsive reading instruction: Flexible intervention for struggling readers in the early grades. Longmont, CO: Sopris West.

Denton, C. A., Nimon, K., Mathes, P. G., Swanson, E. A., Kethley, C., Kurz, T., \& Shih, M. (2010). The effectiveness of a supplemental early reading intervention scaled up in multiple schools. Exceptional Children, 76, 394-416.

Denton, C. A., Wexler, J., Vaughn, S., \& Bryan, D. (2008). Intervention provided to linguistically diverse middle school students with severe reading difficulties. Learning Disabilities Research and Practice, 23, 79-89.

Ehri, L. C. (2002). Phases of acquisition in learning to read words and implications for teaching. In R. Stainthorp \& P. Tomlinson (Eds.), Learning and teaching reading (pp. 7-28). London: British Journal of Educational Psychology Monograph Series II.

Ehri, L.C., Nunes, S. R., Stahl, S. A., \& Willows, D. M. (2001). Systematic phonics instruction helps students learn to read: Evidence from the National Reading Panel's meta-analysis. Review of Educational Research, 7l(3), 393-447.

Ehri, L. C., Satlow, E., \& Gaskins, I. W. (2009). Grapho-phonemic enrichment strengthens keyword analogy instruction for struggling young readers. Reading \& Writing Quarterly, 25, 162-191.

Elbaum, B., Vaughn, S., Hughes, M. T., \& Moody, S. W. (2000). How effective are one-to-one tutoring programs in reading for elementary students at risk for reading failure? Journal of Educational Psychology, 92, 605-619.

Fletcher, J. M., Lyon, G. R., Fuchs, L. S., \& Barnes, M. A. (2007). Learning disabilities: From identification to intervention. New York: Guilford Press.

Fletcher, J. M., Stuebing, K. K., Barth, A. E., Denton, C. A., Cirino, P. T., Francis, D. J., \& Vaughn, S. (in press). Cognitive correlates of inadequate response to reading intervention. School Psychology Review.

Foorman, B. R., Chen, D., Carlson, C., Moats, L., Francis, D. J., \& Fletcher, J. M. (2003). The necessity of the alphabetic principle to phonemic awareness instruction. Reading and Writing: An Interdisciplinary Journal, 16, 289-324.

Foorman, B. R., Francis, D. J., Fletcher, J. M., Schatschneider, C., \& Mehta, P. (1998). The role of instruction in learning to read: Preventing reading failure in at-risk children. Journal of Educational Psychology, 90, 37-55.

Foorman, B. R., \& Torgesen, J. (2001). Critical elements of classroom and small-group instruction promote reading success in all children. Learning Disabilities Research \& Practice, 16, 203-212. 
Fountas, I. C. \& Pinnell, G. S. (1996). Guided Reading. Portsmouth, $\mathrm{NH}$ : Heinemann.

Francis, D. J., Santi, K. L., Barr, C., Fletcher, J. M., Varisco, A., \& Foorman, B. R. (2008). Form effects on the estimation of students' oral reading fluency using DIBELS. Journal of School Psychology, 46, 315-342.

Francis, D. J., Shaywitz, S. E., Stuebing, K. K., Shaywitz, B. A., \& Fletcher, J. M. (1996). Developmental lag versus deficit models of reading disability: A longitudinal, individual growth curve analysis. Journal of Educational Psychology, 88(1), 3-17.

Fuchs, L. S., Deno, S. L., \& Mirkin, P. K. (1984). The effects of frequent curriculum-based measurement and evaluation on pedagogy, student achievement, and student awareness of learning. American Educational Research Journal, 21, 449-460.

Fuchs, L. S., Fuchs, D., Hosp, M. D., \& Jenkins, J. (2001). Oral reading fluency as an indicator of reading competence: A theoretical, empirical, and historical analysis. Scientific Studies of Reading, 5 , 239-259.

Gaskins, I., Ehri, L., Cress, C., O'Hara, C., \& Donnelly, K. (1997). Procedures for word learning: Making discoveries about words. The Reading Teacher, 50, 312-327.

Gersten, R., Compton, D., Connor, C. M., Dimino, J., Santoro, L., Linan-Thompson, S., \& Tilly, W. D. (2008). Assisting students struggling with reading: Response to Intervention and multi-tier intervention for reading in the primary grades. A practice guide. (NCEE 2009-4045). Washington, DC: National Center for Education Evaluation and Regional Assistance, Institute of Education Sciences, US Department of Education. Retrieved from http:// ies.ed.gov/ncee/wwc/publications/practiceguides/.

Gough, P. B., \& Tunmer, W. E. (1986). Decoding, reading, and reading disability. Remedial \& Special Education, 7, 6-10. doi:10.1177/ 074193258600700104

Gough, P., \& Walsh, S. (1991). Chinese, Phoenicians, and the orthographic cipher of English. In S. Brady \& D. Shankweiler, (1991). Phonological processes in literacy: A tribute to Isabelle Y. Liberman. Hillsdale, NJ: Erlbaum.

Hanushek, E. A., Kain, J. F., \& Rivkin, S. G. (1998). Does special education raise academic achievement for students with disabilities? National Bureau of Economic Research, Working Paper No. 6690, Cambridge, MA. Retrieved from www.nber.org/papers/w6690

Hasbrouck, J. (2008). Quick phonics screener. St. Paul, MN: Read Naturally.

Hiebert, E. H., \& Fisher, C. W. (2002, April). Text matters in developing reading fluency. Paper presented at the International Reading Association, San Francisco, CA.

Iversen, S., \& Tunmer, W. E. (1993). Phonological processing skills and the reading recovery program. Journal of Educational Psy. chology, 85, 112-126.

Iversen, S., Tunmer, W. E., \& Chapman, J. W. (2005). The effects of varying group size on the Reading Recovery approach to preventative early intervention. Journal of Learning Disabilities, 38(5), $456-472$.

Jenkins, J. R., Graff, J. J., \& Miglioretti, D. L. (2009). Estimating reading growth using intermittent $\mathrm{CBM}$ progress monitoring. Exceptional Children, 75, 151-163.

Jenkins, J. R., Hudson, R. F., \& Johnson, E. S. (2007). Screening for at-risk readers in a response to intervention framework. School Psychology Review, 36, 582-600.

Jenkins, J. R., Peyton, J. A., Sanders, E. A., \& Vadasy, P. F. (2004). Effects of reading decodable texts in supplemental first-grade tutoring. Scientific Studies of Reading, 8(1), 53-85.
Juel, C. (1988). Learning to read and write: A longitudinal study of 54 children from first through fourth grades. Journal of Educational Psychology, 80, 437-447.

Levy, B. A., Abello, B., \& Lysynchuk, L. (1997). Transfer from word training to reading in context: Gains in reading fluency and comprehension. Learning Disability Quarterly, 20, 173-188.

Lou, Y., Abrami, P. C., Spence, J. C., Poulson, C., Chambers, B., \& d'Appollonia, S. (1996). Within-class grouping: A meta-analysis. Review of Research, 66, 423-458.

Lovett, M. W., Lacerenza, L., Borden, S. L., Frijters, J. C., Seteinbach, K. A., \& DePalma, M. (2000). Components of effective remediation for developmental reading disabilities: combining phonological and strategy-based instruction to improve outcomes. Journal of Educational Psychology, 92, 263-283.

Mathes, P. G., Denton, C. A., Fletcher, J. M., Anthony, J. L., Francis, D. J., \& Schatschneider, C. (2005). The effects of theoretically different instruction and student characteristics on the skills of struggling readers. Reading Research Quarterly, 40, 148-182.

McCray, A. D., Vaughn, S., \& Neal, L. I. (2001). Not all students learn to read by third grade: Middle school students speak out about their reading disabilities. Journal of Special Education, 35(1), 17-30.

Meyer, M. S., \& Felton, R. H. (1999). Repeated reading to enhance fluency: Old approaches and new directions. Annals of Dyslexia, 49. 283-306.

National Reading Panel (NRP). (2000). Teaching children to read: evidence-based assessment of the scientific research literature on reading and its implications for reading instruction. Bethesda, MD: National Reading Panel, National Institute of Child Health and Human Development.

Nelson, J. R., Benner, G. J., \& Gonzalez, J. (2003). Learner characteristics that influence the treatment effectiveness of early literacy interventions: A meta-analytic review. Learning Disabilities Research \& Practice, 18, 255-267.

Osborn, S. (1995). Reading Mastery series guide. (Rainbow Edition). Columbus, OH: SRA/McGraw-Hill.

Piasta, S. B., Connor, C. M., Fishman, B., \& Morrison, F. J. (2009). Teachers' knowledge of literacy concepts, classroom practices, and student reading growth. Scientific Studies of Reading, 13, 224-248.

Reitsma, P. (1990). Development of orthographic knowledge. In P. Reitsma \& L. Verhoeven (Eds.), Acquisition of reading in Dutch (pp. 43-64). Dordrecht: Foris.

Roswell, F. G., Chall, J. S., Curtis, M. E., \& Kearns, G. (2005), Diagnostic assessments of reading: Itasca, IL: Riverside.

Schatschneider, C., Fletcher, J. M., Francis, D. J., Carlson, C. D., \& Foorman, B. R. (2004). Kindergarten prediction of reading skills: A longitudinal comparative analysis. Journal of Educational Psychology, 96, 265-282.

Shapiro, E. S. (2004). Academic skills problems: Direct assessment and intervention (3rd ed.). New York: Guilford Press.

Shaywitz, S. (2003). Overcoming dyslexia. New York: Knopf.

Simos, P. G., Fletcher, J. M., Bergman, E., Breier, J. I., Foorman, B. R., Castillo, E. M., et al. (2002). Dyslexia-specific brain activation profile becomes normal following successful remedial training. Neurology. 58, 1-10.

Snow, C. E. (2002). Reading for understanding: Toward an $R$ \& $D$ program for comprehension. Santa Monica, CA: RAND.

Snow, C. E., Burns, M. S., \& Griffin, P. (Eds.). (1998). Preventing reading difficulties in young children. Washington, DC: National Academy Press. 


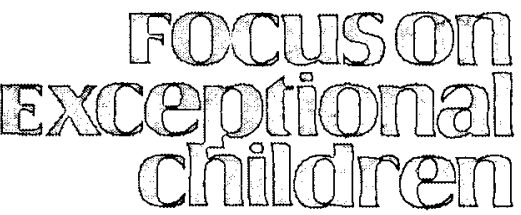

Sprick, M. M., Howard, L. M., \& Fidanque, A. (1998). Read well: Critical foundations in primary reading. Longmont, $\mathrm{CO}$ : Sopris West.

Stanovich, K. (1986). Matthew effects in reading: Some consequences of individual differences in the acquisition of literacy. Reading Research Quarterly, 21, 360-407.

Stecker, P. M., Fuchs, L. S., \& Fuchs, D. (2005). Using curriculumbased measurement to improve student achievement: Review of research. Psychology in the Schools, 42, 795-820.

Swanson, H. L. (1999). Reading research for students with LD: A meta-analysis of intervention outcomes. Journal of Learning Disabilities, 32(6), 504-532.

Sweet, A. P., \& Snow, C. (2002). Reconceptualizing reading comprehension. In C. C. Block, L. B. Gambrell, \& M. Pressley (Eds.), Improving reading comprehension instruction: Rethinking research, theory, and classroom practice (pp. 17-53). San Francisco, CA: Jossey-Bass.

Taylor, B. M., Pearson, P. D., Clark, K. E., \& Walpole, S. (1999). Beating the odds in teaching all children to read. (CIERA Rep. No. 2006). Ann Arbor, MI: Center for Improvement of Early Reading Achievement.

Torgesen, J. K. (2004). Lessons learned from research on interventions for students who have difficulty learning to read. In P. McCardle $\& \mathrm{~V}$. Chhabra (Eds.) The voice of evidence in reading research (pp. 355-382). Baltimore: Brookes.

Torgesen, J. K. (2005). Remedial interventions for students with dyslexia: National goals and current accomplishments. In S. Richardson \& J. Gilger (Eds.), Research-based education and intervention: What we need to know (pp. 103-124). Boston: International Dyslexia Association.

Torgesen, J. K., Alexander, A. W., Wagner, R. K., Rashotte, C. A., Voeller, K., Conway, T., \& Rose, E. (2001). Intensive remedial instruction for children with severe reading disabilities: Immediate and long-term outcomes from two instructional approaches. Journal of Learning Disabilities, 34, 33-58.

Torgesen, J. K., \& Burgess, S. R. (1998). Consistency of readingrelated phonological processes throughout early childhood: Evidence from longitudinal-correlational and instructional studies. In J. L. Metsala \& L. C. Ehri (Eds.), Word recognition in beginning literacy (pp. 161-188). Malhwah, NJ: Erlbaum.
Torgesen, J. K., Rashotte, C. A., Alexander, A., Alexander, J., \& MacPhee, K. (2003). Progress towards understanding the instructional conditions necessary for remediating reading difficulties in older children. In B. Foorman (Ed.). Preventing and remediating reading difficulties: Bringing science to scale. (pp. 275-298). Parkton, MD: York Press.

Torgesen, J. K., Wagner, R. K., \& Rashotte, C. A. (1999). Test of Word Reading Efficiency. Austin, TX: Pro-Ed.

Vaughn, S. R., Cirino, P. T., Wanzek, J., Wexler, J., Fletcher, J. M., Denton, C. A., ... Francis, D. J. (2010). Response to intervention for middle school students with reading difficulties: Effects of a primary and secondary intervention. School Psychology Review, 39(1), 3-21.

Vaughn, S., Denton, C. A., \& Fletcher, J. M. (2010). Why intensive interventions are necessary for students with severe reading difficulties. Psychology in the Schools, 47(5), 432-444.

Vaughn, S., \& Linan-Thompson, S. (2003). Group size and time allotted to intervention: Effects for students with reading difficulties. In B. Foorman (Ed.), Preventing and remediating reading difficulties: Bringing science to scale. Austin, TX: Pro-Ed.

Vaughn, S., Wanzek, J., Murray, C.S., Scammacca, N., Linan-Thompson, S., \& Woodruff, A. L. (2009). Response to early reading intervention examining higher and lower responders. Exceptional Children, 75(2), 165-183.

Vygotsky, L. S. (1978). Mind and society: The development of higher mental processes. Cambridge, MA: Harvard University Press.

Wanzek, J., \& Vaughn, S. (2007). Research-based implications from extensive early reading interventions. School Psychology Review, 36, 541-561.

Wanzek, J., Wexler, J., Vaughn, S., \& Ciullo, S. (2010). Reading interventions for struggling readers in the upper elementary grades: $A$ synthesis of 20 years of research. Reading and Writing: An Interdisciplinary Journal, 23, 889-912.

Warren, S. F., Fey, M. E., \& Yoder, P. J. (2007). Differential treatment intensity research: A missing link to creating optimally effective communication interventions. Mental Retardation and Developmental Disabilities Research Reviews, 13(1), 70-77.

Woodcock, R. (1987). Woodcock Reading Mastery Test-Revised. Circle Pines, MN: American Guidance Service.

\section{PERMISSIONS AND COPYRIGHT}

All rights are reserved. No part of this publication may be reproduced, photocopied, faxed, stored in a retrieval system, or transmitted in any form or by any means, electronic, mechanical, recording or otherwise, without the prior written permission of the publisher.
Back issues are available for sale. Reproduction requires permission and payment of fees. It is illegal and a violation of federal copyright law to reproduce this publication without permission. Direct all inquiries to the permissions editor. 